Pacific Journal of Mathematic 


\section{BIORTHOGONAL SYSTEMS IN BANACH SPACES}

S. R. FOGUEL

1. Introduction. We shall be interested, in this paper, in the following question: Given a biorthogonal system $\left(x_{n}, f_{n}\right)$ in a separable Banach space $B$, under what conditions can one assert that the sequence $\left\{x_{n}\right\}$ constitutes a basis? The system $\left(x_{n}, f_{n}\right)$ is called a biorthogonal system if

$$
x_{n} \in B, f_{n} \in B^{*} \text { and } f_{n}\left(x_{m}\right)=\delta_{n m} .
$$

We shall assume throughout the paper that $\left\|x_{n}\right\|=1$ and the sequence $\left\{x_{n}\right\}$ is fundamental. When the sequence $\left\{x_{n}\right\}$ constitutes a basis it will be called regular otherwise irregular.

2. Irregular systems. Let $\left\{x_{n}\right\}$ be an irregular sequence. (For example the trigonometric functions for $C(-\pi, \pi)$ ). The following definitions will be used.

$$
\begin{gathered}
\varphi_{n}(x)=\sum_{i=1}^{n} f_{i}(x) x_{i} \\
\|\| x \|=\sup \left\{\left\|\varphi_{n}(x)\right\|, n=1,2,3, \cdots\right\}
\end{gathered}
$$

Compare [4]

$$
\begin{aligned}
& E_{0}=\left\{x \mid \lim _{n \rightarrow \infty} \varphi_{n}(x)=x\right\} \\
& E_{1}=\{x|\|x \mid\|<\infty\} \\
& E_{2}=\left\{x \mid \lim _{n \rightarrow \infty}\left\|\varphi_{n}(x)\right\|=\infty\right\} \\
& E_{3}=\{x \mid\|x\|=\infty\} .
\end{aligned}
$$

We have $E_{0} \subset E_{1}$ and $E_{2} \subset E_{3}$. For regular systems $E_{0}=E_{1}=B$ and $E_{2}=E_{3}=\phi$ where $\phi$ is the null set. The system is regular if and only if the sequence $\left\{\left\|\varphi_{n}\right\|\right\}$ is bounded [2], and if the sequence $\left\{\left\|\varphi_{n}\right\|\right\}$ is not bounded the set

$$
\bigcap_{n=1}^{\infty}\left\{x \mid\left\|\varphi_{n}(x)\right\| \leqq K\right\}
$$

is nowhere dense [2], hence for irregular systems the set

$$
E_{1}=\bigcup_{k=1} \bigcap_{n=1}\left\{x \mid\left\|\varphi_{n}(x)\right\| \leqq K\right\}
$$

is of the first category. Also $E_{3}=B-E_{1}$ is dense and of the second

Received February 22, 1956. This paper is part of a dissertation presented for the degree of Doctor of Philosophy Yale University. 
category. In the case of regular systems there exists a number $K \geqq 1$ such that if $\|x\|=1$ then $1 \leqq\|x\| \mid \leqq K$. The existence of such a bound, $K$, is equivalent to the equiboundedness of $\left\{\left\|\varphi_{n}(x)\right\|\right\}\|x\|=1$ and therefore for irregular systems for any number $a$, there exists a point $x$ such that $\|x\|=1$ and $\|x\| \|>a$, moreover such a point might be found in the linear manifold generated by $\left\{x_{n}\right\}$. (Equiboundedness of $\left\{\left\|\varphi_{n}(x)\right\|\right\}$ on a dense subset of the unit sphere would imply equiboundedness on the unit sphere.) It is interesting to note that for every number $a \geqq 1$ there exists a point $x$ such that $\|x\|=1$ and $\|x\| \|=a$. There exists a point $y_{n}$ satisfying

$$
y_{n}=\sum_{i=1}^{n} a_{i} x_{i},\left\|y_{n}\right\|=1,\left\|y_{n}\right\|>>a .
$$

On the other hand $\left\|x_{1}\right\|=1$ and $\left\|\mid x_{1}\right\|=1$. Let $0 \leqq t \leqq 1$, then $(1-t) x_{1}+$ $t y_{n} \neq 0$. Define

$$
g_{\nu}(t)=\left\|\varphi_{\nu}\left(\frac{(1-t) x_{1}+t y_{n}}{\left\|(1-t) x_{1}+t y_{n}\right\|}\right)\right\| \quad \nu=12 \cdots n
$$

The functions $g_{\nu}(t)$ are continuous in $t$, and so is $g(t)$ where

$$
\begin{aligned}
& g(t)=\sup \left\{g_{\nu}(t) \mid 1 \leqq \nu \leqq n\right\} . \\
& g(0)=1
\end{aligned}
$$

and

$$
g(1)=\sup \left\{\left\|\varphi_{\nu}\left(y_{n}\right)\right\| 1 \leqq \nu \leqq n\right\}=\left\|y_{n}\right\|>a .
$$

There exists a number $t_{0}$ such that

$$
0 \leqq t_{0}<1 \text { and } g\left(t_{0}\right)=a .
$$

This following generalization of Baire's theorem [1] will be used : Let $\left\{u_{n}(x)\right\}$ be a sequence of real valued continuous functions defined on a metric space $c$, and $\lim u_{n}(x)=u(x),\left|u_{n}(x)\right| \leqq M$, then the set of points of discontinuity of $u$ is of the first category.

TheOREM 1. The set $E_{2}$ is of the first category.

Proof. Define the functions $u_{n}(x)$ by

$$
u_{n}(x)=\frac{\left\|\varphi_{n}(x)\right\|}{1+\left\|\varphi_{n}(x)\right\|} .
$$

We have $0 \leqq u_{n}(x) \leqq 1$ and if $x \in E_{0} \cup E_{2}$ then

$$
\lim u_{n}(x)=u(x)
$$


where $u(x)=1$ for $x \in E_{2}$ and

$$
u(x)=\frac{\|x\|}{1+\|x\|} \text { for } x \in E_{0} .
$$

If $E_{2}$ is a set of the second category then there exists at least one point of continuity of $u$. Let us denote such a point by $x_{0}$.

The set $E_{0}$ is dense in $B$. Let $\left\{y_{n}\right\}$ by a sequence of points in $E_{0}$ with $\lim y_{n}=x_{0}$, then

$$
u\left(x_{0}\right)=\lim u\left(y_{n}\right)=\lim \frac{\left\|y_{n}\right\|}{1+\left\|y_{n}\right\|}=\frac{\left\|x_{0}\right\|}{1+\left\|x_{0}\right\|}
$$

The set $E_{2}$ is dense in $B$. If $x \in E_{2}$ and $y \in E_{0}$ then $x+y \in E_{2}$. Let $\left\{z_{n}\right\}$ be a sequence of points in $E_{2}$ with $\lim z_{n}=x_{0}$, then $u\left(z_{n}\right)=1$ and

$$
\frac{\left\|x_{0}\right\|}{1+\left\|x_{0}\right\|}=u\left(x_{0}\right)=\lim u\left(z_{n}\right)=1
$$

which is absurd.

THEOREM 2. Let $S$ be a subset of $B$ such that each point $x \in S$ is the limit of some sequence $\left\{y_{n}\right\}, y_{n} \in B$, and the sequence $\left\{\left\|\mid y_{n}\right\|\right\}$ is bounded, then $S$ is of the first category.

Proof. Define the functions $v_{n}(x)$ by

$$
v_{n}(x)=\frac{\|\| \varphi_{n}(x) \| \mid}{1+\left\|\varphi_{n}(x)\right\| \|}
$$

then $0 \leqq v_{1}(x) \leqq v_{2}(x) \leqq \cdots<1$. If $x \in B$ let $\lim v_{n}(x)=v(x) . \quad v(x)=1$ for $x \in E_{3}$ and the set $E_{3}$ is dense, hence $v(x)=1$ at every point of continuity of $v$. Let $x$ be a point of continuity of $v$ and $\left\{z_{n}\right\}$ a sequence with $\lim z_{n}=x$, then

$$
\lim v\left(z_{n}\right)=v(x)=1
$$

therefore the sequence $\left\{||\left|z_{n}\right| \|\right\}$ is unbounded. Thus the set $S$ is contained in the set of points of discontinuity of $v$ which is a set of the first category by Baire's theorem.

3. General criteria for regularity. From Theorems 1 and 2 we derive the following criteria.

THEOREM 3. A necessary and sufficient condition for the regularity of the system $\left(x_{n}, f_{n}\right)$ is. 


$$
\sup \left\{\left\|\varphi_{n}(x)\right\|, n=1,2, \cdots\right\}=\infty
$$

implies

$$
\lim \left\|\varphi_{n}(x)\right\|=\infty . \quad\left(\text { or } E_{2}=E_{3}\right)
$$

Proof. If the system is regular, then $E_{2}=E_{3}=\phi$. On the other hand, if the system is irregular $E_{2}$ is of the first category and $E_{3}$ of the second category.

Let

$$
\psi_{n}(x)=\sum_{i=1}^{n} a_{i}^{n} x_{i}
$$

denote the point nearest to $x$ on the subspace spanned by

$$
\left\{x_{1}, x_{2}, x_{3}, \cdots, x_{n}\right\}
$$

THEOREM 4. The system $\left(x_{n}, f_{n}\right)$ is regular if and only if the sequence $\left\{\left\||| \psi_{n}(x)\right\| \|\right\}$ is bounded for each $x$.

Proof. If the system is regular, then there exists a positive number $K$, such that $\|x\| \leqq K\|x\|$. Then

$$
\|\| \psi_{n}(x)\|\| \leqq K\left\|\psi_{n}(x)\right\| \leqq K\left(\|x\|+\left\|x-\psi_{n}(x)\right\|\right) \leqq K 2\|x\|,
$$

hence the condition is necessary. Sufficiency is clear by Theorem 2 .

4. Biorthogonal systems in Hilbert spaces. In this section we assume that $B$ is a Hilbert space. In order to use Theorem 4 let us compute $\left\|\psi_{n}(x)\right\| \| . \quad \phi_{n}(x)=\sum_{i=1}^{n} \alpha_{\imath}^{n} x_{i}$ and the coefficient $\alpha_{i}^{n}$ may be computed from the equation

$$
\left(x-\sum_{i=1}^{n} a_{i}^{n} x_{i}, x_{k}\right)=0 \quad k=1,2, \cdots, n
$$

or

$$
\left(x, x_{k}\right)=\sum_{i=1}^{n} a_{i}^{n}\left(x_{i}, x_{k}\right)
$$

We introduce the following notation

$$
\begin{gathered}
\left(x_{i}, x_{k}\right)=c_{i k} \\
C_{n}=\left(c_{i k}\right) \quad 1 \leqq i \leqq n \quad 1 \leqq k \leqq n \\
\left(\left(x, x_{i}\right),\left(x, x_{2}\right), \cdots,\left(x, x_{n}\right)\right)=(\gamma)_{n} \\
\left(a_{1}^{n}, a_{2}^{n}, \cdots, a_{n}^{n}\right)=(a)_{n}
\end{gathered}
$$

Then 


$$
(\gamma)_{n}=(a)_{n} C_{n} \quad \text { or } \quad(a)_{n}=(\gamma)_{n} C_{n}^{-1}
$$

since $C_{n}^{-1}$ exists. Now

$$
\left\|\sum_{i=1}^{j} a_{i}^{n} x_{i}\right\|^{2}=\sum_{i, k=1}^{j} a_{i}^{n} \overline{a_{k}^{n}} c_{i \varepsilon}=(a)_{n} E_{j}^{n} C_{n} E_{j}^{n}(a)_{n}^{*}
$$

where $E_{j}^{n}$ is the matrix $\left(e_{l, m}\right)$ with

$$
e_{l, m} \begin{cases}1 & l=m \leqq j \\ 0 & \text { otherwise }\end{cases}
$$

$C_{n}^{*}=C_{n}$ and $(a)_{n}=(\gamma)_{n} C_{n}^{-1}$ hence

$$
\left\|\sum_{j=1}^{j} a_{i}^{n} x_{i}\right\|^{2}=(\gamma)_{n} C_{n}^{-1} E_{j}^{n} C_{n} E_{j}^{n} C_{n}^{-1}(\gamma)_{n}^{*}
$$

Orthogonalizing the sequence $\left\{x_{n}\right\}$ by Schmidt's process we get the sequence $\left\{y_{n}\right\}$ with

$$
x_{1}=y_{1} \quad x_{k}=\sum_{\alpha=1}^{k} d_{k, \alpha} y_{\alpha}
$$

where

$$
d_{k, \alpha}= \begin{cases}\left(x_{k}, y_{\alpha}\right) & \alpha \leqq k \\ 0 & \alpha>k\end{cases}
$$

and $d_{11}=1$ see [3].

Let $D_{n}$ denote the triangular matrix

$$
\begin{gathered}
\left(d_{k, \alpha}\right) \quad 1 \leqq \alpha \leqq n \quad 1 \leqq k \leqq n \\
\left(x_{i}, x_{j}\right)=\sum_{\alpha} d_{i, \alpha} \overline{d_{j, \alpha}} \text { or } C_{n}=D_{n} D_{n}^{*} .
\end{gathered}
$$

The matrix $D_{n}$ can be computed from this relation.

Let

$$
\begin{gathered}
(\delta)_{n}=\left(\left(x, y_{1}\right),\left(x, y_{2}\right), \cdots,\left(x, y_{n}\right)\right) \\
\left(x, x_{k}\right)=\sum_{\alpha=1}^{k}\left(x, y_{\alpha}\right) \bar{d}_{k, \alpha} \text { or }(\gamma)_{n}=(\delta)_{n} D_{n}^{*}
\end{gathered}
$$

and hence

$$
\begin{aligned}
\left\|\sum_{i=1}^{j} a_{i}^{n} x_{i}\right\|^{2} & =(\gamma)_{n} C_{n}^{-1} E_{j}^{n} C_{n} E_{j}^{n} C_{n}^{-1}(\gamma)_{n}^{*}=(\delta)_{n} D_{n}^{*} C_{n}^{-1} E_{j}^{n} C_{n} E_{j}^{n} C_{n}^{-1} D_{n}(\delta)_{n}^{*} \\
. & =(\delta)_{n}\left(D_{n}^{-1} E_{n}^{j} D_{n}\right)\left(D_{n}^{*} E_{j}^{n}\left(D_{n}^{*}\right)^{-1}\right)(\delta)_{n}^{*}
\end{aligned}
$$

Let $A_{j}^{n}=D_{n}^{-1} E_{j}^{n} D_{n}$ then 


$$
||\left|\psi_{n}(x)\right| \| \mid=\max \left\{(\delta)_{n} A_{j}^{n}\left(A_{j}^{n}\right)^{*}(\delta)_{n}^{*} \mid 1 \leqq j \leqq n\right\}
$$

The triangular matrix $A_{j}^{n}$ is an operator defined on the Hilbert space. If

$$
x=\sum_{i=1}^{\infty} \delta_{i} y_{i}
$$

then

$$
A_{j}^{n}(x)=\left(\delta_{1}, \cdots, \delta_{n}\right) A_{j}^{n} .
$$

By Theorem 4 and the above computation the system is regular if and only if for each $x$

$$
\sup \left\{\left\|A_{j}^{n}(x)\right\| \mid 1 \leqq j \leqq n n=12 \cdots\right\}<\infty
$$

or by the uniform boundedness theorem.

THEOREM 5. The system is regular if and only if the double sequence $\left\{\left\|A_{j}^{n}\right\|\right\}$ is bounded, or, in other words, if and only if the set of characteristic roots of $A_{j}^{n}\left(A_{n}^{n}\right)^{*}$ is bounded.

We shall use Theorem 3 to derive the following theorems.

Theorem 6. The system $\left(x_{i}, f_{i}\right)$ is regular and $\sum_{i=1}^{\infty}\left|f_{i}(x)\right|^{2}<\infty$ if and only if for every $x \in B$ there exists a real number $\alpha=\alpha(x)$ such that

$$
2 \Re\left\{\sum_{i=1}^{n} \sum_{j=1}^{i-1} f_{i}(x) f_{j}(x) c_{i j}\right\}>\alpha
$$

Proof. If the system is regular and

$$
\begin{aligned}
\sum_{i=1}^{\infty}\left|f_{i}(x)\right|^{2} & <\infty \text { then } \\
\|x\|^{2}-\sum\left|f_{i}(x)\right|^{2} & =\sum_{i \neq j} f_{i}(x) f_{j}(x) c_{i j} \\
& =2 \Re\left\{\sum_{j<i} f_{i}(x) f_{j}(x) c_{i j}\right\}
\end{aligned}
$$

Therefore the necessity of condition (1) is verified. Assume that condition (1) is satisfied then

$$
\begin{aligned}
\left\|\varphi_{n+p}(x)\right\|^{2} & =\sum_{i j=1}^{n+p} f_{i}(x) f_{j}(x) c_{i j} \\
& =\left\|\varphi_{n}(x)\right\|^{2}+\sum_{i=n+1}^{n+p}\left|f_{i}(x)\right|^{2}+2 \Re\left\{\sum_{i=n+1}^{n+p} \sum_{j=1}^{i-1} f_{i}(x) f_{j}(x) c_{i j}\right\} \\
& \geqq\left\|\varphi_{n}(x)\right\|^{2}+2 \alpha
\end{aligned}
$$


Therefore $\sup _{n}\left\|\varphi_{n}(x)\right\|=\infty$ implies $\lim \left\|\varphi_{n}(x)\right\|=\infty$. According to Theorem 3 the system is regular.

Moreover

$$
\begin{aligned}
\sum_{i=1}^{n}\left|f_{i}(x)\right|^{2} & =\left\|\varphi_{n}(x)\right\|^{2}-2 \Re\left\{\sum_{j<i \leqq n} c_{i j} f_{i}(x) f_{j}(x)\right\} \\
& \leqq\|x\| \|^{2}-\alpha<\infty .
\end{aligned}
$$

An immediate consequence is the following. The system is regular if $\sum_{i \neq j}\left|c_{i j}\right|<\infty$ and the sequence $\left\{\left\|f_{i}\right\|\right\}$ is bounded.

Professor R. C. James called my attention to the fact that this may be proved directly and without the assumption of boundedness of the sequence $\left\{\left\|f_{i}\right\|\right\}$ as follows. We may assume without loss of generality that $\sum_{i \neq j}\left|c_{i j}\right|=r<1$

$$
\begin{aligned}
& \left|\sum_{i \neq j}^{n} a_{i} \bar{a}_{j} c_{i j}\right| \leqq \max \left|a_{i} \overline{a_{j}}\right| \cdot r \leqq \sum_{i=1}^{n}\left|a_{i}\right|^{2} r \\
& \left\|\sum_{i=1}^{n} a_{i} x_{i}\right\|^{2}=\sum_{i=1}^{n}\left|a_{i}\right|^{2}+\sum_{i \neq j}^{n} a_{i} \overline{a_{j}} c_{i j} \leqq 2 \sum_{i=1}^{n}\left|a_{i}\right|^{2}
\end{aligned}
$$

Hence

$$
\begin{aligned}
& \left\|\sum_{i=1}^{n+p} a_{i} x_{i}\right\|^{2}=\sum_{i=1}^{n+p}\left|a_{i}\right|^{2}+\sum_{i \neq j}^{n+p} a_{i} \overline{a_{j}} c_{i j} \\
& \geqq \sum_{i=1}^{n+p}\left|a_{i}\right|^{2}(1-r) \geqq \sum_{i=1}^{n}\left|a_{i}\right|^{2}(1-r) \\
& \geq \frac{1-\mathbf{r}}{2}\left\|\sum_{i=1}^{n} a_{i} x_{i}\right\|^{2}
\end{aligned}
$$

and by [4] the system is regular.

Using the same method as in Theorem 6 we arrive at the following.

THEOREM 7. The system is regular if and only if for each $x$

$$
\inf _{n, p} \Re\left\{\sum_{i=1}^{n} \sum_{j=n+1}^{p} f_{i}(x) f_{j}(x) c_{i j}\right\}>-\infty
$$

Proof.

$$
\begin{aligned}
\left\|\sum_{i=1}^{n+p} f_{i}(x) x_{i}\right\|^{2} & =\left\|\sum_{i=1}^{n} f_{i}(x) x_{i}\right\|^{2}+\left\|\sum_{i=n+1}^{n+p} f_{i}(x) x_{i}\right\|^{2} \\
& +2 \Re\left\{\left(\sum_{i=1}^{n} f_{i}(x) x_{i}, \sum_{j=n+1}^{n+p} f_{j}(x) x_{j}\right)\right\} .
\end{aligned}
$$

If condition (2) is satisfied then according to Theorem 3 the system is regular. If the system is regular then 


$$
\left|\left(\sum_{i=1}^{n} f_{i}(x) x_{i}, \sum_{j=n+1}^{n+p} f_{j}(x) x_{j}\right)\right| \leqq 2 \||| x||^{2}
$$

As a simple application we note the following.

If $c_{i j}=0$ when $|i-j|>N$ then the system is regular if and only if the sequence $\left\{\left\|f_{i}\right\|\right\}$ is bounded.

\section{REFERENCES}

1. R. Baire, Leçons sur les fonctions discontinues, Paris, Gauthier Villars (1905).

2. S. Banach, Théorie des opérations linéaires, Warszawa (1932).

3. Grunblum and Gourevitch, Sur une propriété de la base dans l'espace de Hilbert, C. R. (Doklady) Acad. Sci. URSS (N.S.) 30 (1941), 289-291.

4. M. M. Grunblum, Sur la théorie des systèmes biorthogonaux, C. R. (Doklady) Acad. Sci. URSS (N.S.) 55 (1947), 287-290.

5. Kaczmarz and Steinhaus, Theorie der Orthogonalreihen, Warszawa (1935) Manografje Matematyczne to VI.

YALE UNIVERSITY 


\section{PACIFIC JOURNAL OF MATHEMATICS}

\section{EDITORS}

H. L. ROYDEN

Stanford University

Stanford, California

R. A. Beaumont

University of Washington

Seattle 5, Washington

\section{A. L. Whiteman}

University of Southern California

Los Angeles 7, California

E. G. Straus

University of California

Los Angeles 24, California

\section{ASSOCIATE EDITORS}
E. F. BECKENBACH
C. E. BURGESS
M. HALL
E. HEWITT

\author{
A. HORN \\ V. GANAPATHY IYER \\ R. D. JAMES \\ M. S. KNEBELMAN
}

L. NACHBIN

I. NIVEN

G. SZEKERES

T. G. OSTROM

M. M. SCHIFFER
F. WOLF

K. YOSIDA

\section{SUPPORTING INSTITUTIONS}

\author{
UNIVERSITY OF BRITISH COLUMBIA \\ CALIFORNIA INSTITUTE OF TECHNOLOGY \\ UNIVERSITY OF CALIFORNIA \\ MONTANA STATE UNIVERSITY \\ UNIVERSITY OF NEVADA \\ OREGON STATE COLLEGE \\ UNIVERSITY OF OREGON \\ UNIVERSITY OF SOUTHERN CALIFORNIA
}

\author{
STANFORD UNIVERSITY \\ UNIVERSITY OF UTAH \\ WASHINGTON STATE COLLEGE \\ UNIVERSITY OF WASHINGTON \\ AMERICAN MATHEMATICAL SOCIETY \\ CALIFORNIA RESEARCH CORPORATION \\ HUGHES AIRCRAFT COMPANY \\ THE RAMO-WOOLDRIDGE CORPORATION
}

Mathematical papers intended for publication in the Pacific Journal of Mathematics should be typewritten (double spaced), and the author should keep a complete copy. Manuscripts may be sent to any of the editors. All other communications to the editors should be addressed to the managing editor, E. G. Straus at the University of California, Los Angeles 24, California.

50 reprints per author of each article are furnished free of charge; additional copies may be obtained at cost in multiples of 50 .

The Pacific Journal, of Mathematics is published quarterly, in March, June, September, and December. The price per volume (4 numbers) is $\$ 12.00$; single issues, $\$ 3.50$. Back numbers are available. Special price to individual faculty members of supporting institutions and to individual members of the American Mathematical Society: $\$ 4.00$ per volume; single issues, $\$ 1.25$.

Subscriptions, orders for back numbers, and changes of address should be sent to Pacific Journal of Mathematics, 2120 Oxford Street, Berkeley 4, California.

Printed at Kokusai Bunken Insatsusha (International Academic Printing Co., Ltd.), No. 10, 1-chome, Fujimi-cho, Chiyoda-ku, Tokyo, Japan.

PUBLISHED BY PACIFIC JOURNAL OF MATHEMATICS, A NON-PROFIT CORPORATION

The Supporting Institutions listed above contribute to the cost of publication of this Journal, but they are not owners or publishers and have no responsibility for its content or policies. 


\section{Pacific Journal of Mathematics}

\section{Vol. 7, No. 2 \\ February, 1957}

William F. Donoghue, Jr., The lattice of invariant subspaces of a completely continuous quasi-nilpotent transformation ................... 1031

Michael (Mihály) Fekete and J. L. Walsh, Asymptotic behavior of restricted extremal polynomials and of their zeros.................... 1037

Shaul Foguel, Biorthogonal systems in Banach spaces ............... 1065

David Gale, A theorem on flows in networks ................... 1073

Ioan M. James, On spaces with a multiplication .................. 1083

Richard Vincent Kadison and Isadore Manual Singer, Three test problems in operator theory .................................... 1101

Maurice Kennedy, A convergence theorem for a certain class of Markoff processes........................................ 1107

G. Kurepa, On a new reciprocity, distribution and duality law ........ 1125

Richard Kenneth Lashof, Lie algebras of locally compact groups ........ 1145

Calvin T. Long, Note on normal numbers .................... 1163

M. Mikolás, On certain sums generating the Dedekind sums and their reciprocity laws ..................................... 1167

Barrett O'Neill, Induced homology homomorphisms for set-valued maps......................................... 1179

Mary Ellen Rudin, A topological characterization of sets of real numbers........................................... 1185

M. Schiffer, The Fredholm eigen values of plane domains 1187

F. A. Valentine, A three point convexity property .........

Alexander Doniphan Wallace, The center of a compact lattice is totally

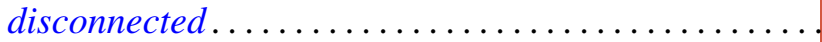

Alexander Doniphan Wallace, Two theorems on topological lattices.

G. T. Whyburn, Dimension and non-density preservation of mappings...

John Hunter Williamson, On the functional representation of certain algebraic systems ... 